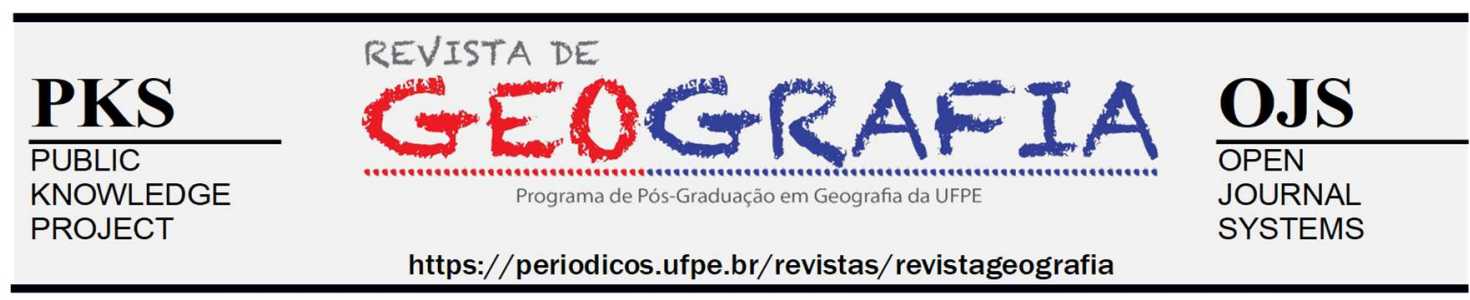

\title{
A EDUCAÇÃO AMBIENTAL E O PAPEL DA HORTA ESCOLAR NA EDUCAÇÃO BÁSICA
}

\author{
Janete Webler Cancelier ${ }^{1}$, Helena Maria Beling 2 , Janete Facco ${ }^{3}$ \\ ${ }^{1}$ Universidade Federal de Santa Maria, E-mail: janetewc@gmail.com \\ ${ }^{2}$ Universidade Federal de Santa Maria,E-mail: helenabeling2015@gmail.com \\ ${ }^{3}$ Universidade Federal de Santa Catarina,E-mail: janetefacco1@gmail.com
}

Artigo recebido em 05/01/2020 e aceito em 27/04/2020

\begin{abstract}
RESUMO
$\mathrm{O}$ artigo apresenta discussões referentes às práticas de educação ambiental, vinculadas às atividades de ensino e condutas pedagógicas na construção e manutenção de hortas no espaço escolar. Os trabalhos foram desenvolvidos a partir de um Projeto de extensão, na perspectiva interdisciplinar, estimulando os alunos a prática de uma alimentação saudável por meio das descobertas, manejo e interação com as diversas fases da construção da horta. As atividades ocorreram em dois anos letivos, sendo o primeiro em 2017 e sequencialmente em 2018, em escolas do ensino fundamental do município de Santa Maria/RS. A estratégia adotada foi o emprego do método indutivo, com abordagem qualitativa. O Projeto Horta na Escola se constitui enquanto instrumento didático - educativo, possibilitando um processo de ensino significativo e uma aprendizagem efetiva a partir da relação entre conteúdos e práticas desenvolvidas. Como resultado, observa-se que em uma escola, a área destinada ao cultivo das verduras e legumes ganhou espaço, bem como, estimulou o interesse educativo, permanecendo em vigor no ano letivo de 2018 e abarcou mais turmas.
\end{abstract}

Palavras-chave: Alimentação saudável; Interdisciplinaridade; Horta urbana; Aprendizagem significativa.

\section{THE ENVIRONMENTAL EDUCATION AND THE ROLE OF SCHOOL GARDENS IN ELEMENTARY EDUCATION}

\begin{abstract}
This article presents discussions about the environmental education practices linked to teaching activities and pedagogical conducts in the construction and maintenance of school gardens. The works were developed from an extension project, into an interdisciplinary perspective, encouraging the students to practice healthy eating through discoveries, management and interactions with many phases of a garden construction. The activities happened in two academic years, the first in 2017 and, sequentially, in 2018, in elementary schools in the city of Santa Maria/RS. The strategy adopted was the inductive method, with a qualitative approach. The Garden at the School Project is a didactic-educational instrument, enabling a meaningful teaching process and an effective learning from the relation between content and practice. As a result, it is observed that in one school, the area designed to vegetables gained more space and stimulated educational interest, remaining in force in the 2018 academic year, as well as included more classes.
\end{abstract}

Keywords: Healthy eating; Interdisciplinarity; Urban garden; Effective learning. 


\section{INTRODUÇÃO}

O presente artigo propõe-se a apresentar atividades desenvolvidas em duas escolas do Ensino Fundamental. O objetivo central foi trabalhar ações vinculadas à educação ambiental com a construção de hortas no espaço escolar a partir de uma aprendizagem significativa.

Conforme a Lei n. 9.795 de 1999, em seu art. 4º a Educação Ambiental é o processo pelo qual os indivíduos e a coletividade constroem valores sociais, conhecimentos e habilidades, tais como: a construção e manutenção de hortas; incentivo a sensibilização em relação a conservação ambiental; estímulo a competências voltadas para a conservação do meio ambiente que é o bem de uso comum do povo, essencial a qualidade de vida e sua sustentabilidade (BRASIL, 1999).

Já para os Parâmetros Curriculares Nacionais (PCNs) para Meio Ambiente e Saúde (BRASIL, 1997) a expressão "Educação Ambiental” passou a qualificar iniciativas de universidades, escolas, instituições governamentais e não-governamentais, por meio das quais se busca, conscientizar setores da sociedade para as questões ambientais.

Por sua vez, a Organização Mundial da Saúde (OMS, 1997) define que uma das melhores formas de promover a saúde é através da escola. Isso porque, a escola é um espaço social onde, muitas pessoas convivem, aprendem e trabalham, considerando ser o lugar em que os estudantes e os professores, passam a maior parte de seu tempo. Ademais, é na escola o espaço em que os programas de educação e saúde podem ter a maior repercussão, beneficiando os alunos na infância e na adolescência. Entende-se que a partir das hortas escolas, torna-se possível materializar a prática ampliando o acesso a alimentos saudáveis, à educação ambiental e a saúde.

Nas atividades escolares desenvolvidas pelo viés da educação ambiental, a horta se configura enquanto um recurso didático que permite relacionar a teoria com a prática. A partir da horta torna-se possível trabalhar os conteúdos de forma transdisciplinar, inter-relacionando conhecimentos vinculados às dimensões ambientais, econômicas, sociais, culturais, políticas, bem como concepções atribuídas ao tipo de alimentação predominante nas sociedades. Por meio da construção e dos cuidados, possibilita que os alunos desenvolvam diferentes habilidades, concepções e práticas frente ao trabalho coletivo, aos alimentos consumidos e sua qualidade. 
O Projeto horta na escola procura incentivar hábitos alimentares saudáveis com a introdução das hortas, vinculando à escola como um espaço de adoção de hábitos saudáveis não só dos alunos, mas também das famílias. Os alunos envolvidos têm a possibilidade de aprenderem conteúdos trabalhados nas salas de aula de forma lúdica e prática, fortalecendo o conhecimento teórico adquirido e estabelecendo relações entre conteúdos trabalhados e as práticas realizadas. Desta forma, a horta se coloca enquanto um laboratório de práticas, onde diferentes atividades didáticas podem ser desenvolvidas. A participação de todos e de cada um dos sujeitos envolvidos nas distintas fases do processo, fortalece o convívio com diferentes grupos e ideias.

Ao mesclar a prática do cultivo de alimentos com conteúdos trabalhados em sala de aula, os alunos aprendem e internalizam novos conceitos de forma lúdica e prática, reforçando o conhecimento teórico adquirido a partir das correlações realizadas. Nesse contexto, o presente relato resulta de um Projeto de Extensão, realizado sem recursos públicos, que objetivou articular a educação ambiental por meio de condutas pedagógicas a partir da construção de hortas no espaço escolar, no município de Santa Maria-RS com alunos do Ensino Fundamental. Buscou-se estimular nos alunos a conscientização ambiental e a inserção de hábitos para uma alimentação saudável por meio das descobertas, manejo e interações com as diversas fases do cultivo de alimentos na horta.

\section{PERCURSOS METODOLÓGICOS}

O municipio onde as atividades se desenvolveram

O município de Santa Maria está localizado na região central do estado do Rio Grande do Sul (RS), conforme Figura 1. Sua configuração territorial está associada ao processo de ocupação e formação socioeconômica da região central do RS.

Santa Maria se caracteriza por ser a $5^{\text {a }}$ cidade mais populosa do Rio Grande do Sul e, isoladamente, a maior de sua região, possuindo no ano de 2018 uma população equivalente à 280.505 habitantes, dos quais $95 \%$ residem no espaço urbano. A taxa de crescimento anual da população gira em torno de $0,69 \%$, segundo estimativas do Instituto Brasileiro de Geografia e Estatística (IBGE, 2019), o que demonstra a atratividade da mesma em relação aos demais municipios que compõem a região central do estado do Rio Grande do Sul. 
Figura 1: Mapa de localização do município de Santa Maria no RS

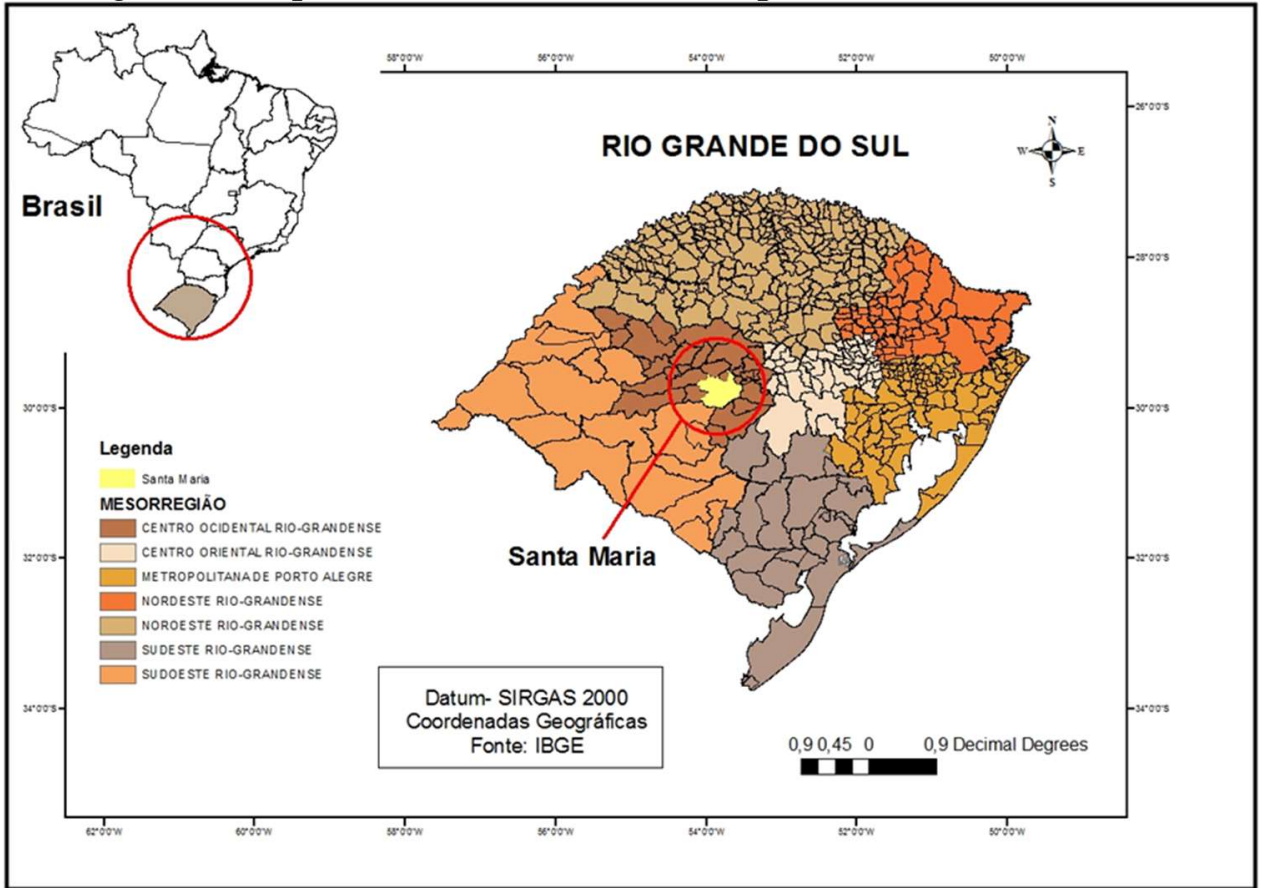

Fonte: IBGE (2010).

Organização: autoras (2019).

A estratégia usada foi o emprego do método indutivo, a partir de uma abordagem qualitativa (interpretativa) que busca compreender os fenômenos a partir da perspectiva dos sujeitos, considerando o ambiente como fonte direta dos dados e o pesquisador como instrumento chave.

O projeto "Horta na Escola" foi desenvolvido em duas escolas de ensino fundamental, localizadas no município de Santa Maria/ RS, entre os anos de 2017 e 2018, sendo uma da rede particular - escola Riachuelo localizada no bairro Camobi e uma da rede municipal - escola Intendente Manoel Ribas, localizada no bairro Santo Antão. Nos dois anos de efetivação do projeto, participaram um total de 18 turmas, totalizando 310 alunos e 10 professores. Cada turma se responsabilizou pelo plantio e manutenção de um canteiro, com apoio do respectivo professor de cada uma das turmas.

A ideia para o desenvolvimento do Projeto partiu de uma das pesquisadoras, que buscava inserir a universidade na escola a partir das ações de extensão com a prática da agricultura urbana. As ações de extensão propostas, buscaram promover a qualificação da escola na perspectiva da troca de saberes e experiências entre os sujeitos envolvidos. Entende-se que a base das práticas educacionais deve partir do espaço em que vive o aluno, objetivando a inserção deste no processo educativo, de modo vivo e 
dinâmico (FREIRE, 1999). As atividades iniciaram no ano de 2017 em uma escola da rede particular se estendendo no ano de 2018 à uma escola da rede pública de ensino, ambas já supracitadas.

A escolha da escola da rede particular ocorreu por esta concordar em participar do projeto, assumindo todos os custos das mudas, adubos e demais materiais que se fizessem necessários para a construção da horta, bem como, autorizar o desenvolvimento das atividades e oficinas no período em que os alunos estão na escola. Cabe salientar que, este projeto se desenvolveu sem nenhum recurso público. A contrapartida das pesquisadoras ocorreu na realização, de forma voluntária, das oficinas, da construção da horta e o acompanhamento semanal em todas as atividades e fases do projeto. A escola pública se insere no projeto em menor proporção pela dificuldade em conseguir organizar, junto da mesma, os horários para o desenvolvimento das atividades, assim como o material e recursos necessários.

\section{O público}

As atividades desenvolvidas durante o ano letivo de 2017, envolveram alunos do ensino fundamental séries iniciais ( $3^{\circ}$ ao $4^{\circ}$ ano), sete turmas, totalizando 120 alunos e quatro professoras. No ano de 2018, participaram 11 turmas entre duas escolas, totalizando 190 alunos e seis professoras. Para cada turma, uma aula semanal intercalada entre a parte teórica e a prática.

Em um primeiro momento, ocorreram conversas com os alunos e uma problematização inicial sobre a importância da alimentação saudável, a origem dos legumes e verduras, formas de cultivo, formatos das hortas, o que pode ser cultivado em nossas residências e materiais necessários para fazer uma horta. Com isso, buscou-se identificar quais eram os conhecimentos prévios que os alunos possuíam a respeito: relação entre a horta alimentação saudável e saúde; a relação entre cultivo de alimentos e meio ambiente; as formas de controle de pragas que atacam as hortas; a possibilidade de produzir alimentos sem utilizar agroquímicos.

Foi apresentado aos alunos os objetivos e propósitos da construção da horta ser no espaço escolar, assim como o papel deles (alunos) e sua responsabilidade perante a concretização desse projeto. Quanto aos hábitos alimentares, uma de suas dimensões é a incorporação no meio ambiente feita pelo ser humano por meio do ato de comer, de tal forma que o ambiente passa a compô-lo e este passa a compor o ambiente, o que resulta 
em um ser constituinte e constituído (OLIVEIRA; PEREIRA; PEREIRA JUNIOR, 2018).

A partir do diálogo foi possível observar que a maior parte dos alunos não tinha conhecimento da origem dos alimentos, das formas de cultivo, o manejo adequado, a qualidade dos mesmos, sendo o supermercado a referência para a aquisição dos alimentos. Com este procedimento tornou-se possível planejar as ações a serem desenvolvidas.

No ano de 2018, além da escola da rede particular, as ações se estendem à escola Intendente Manoel Ribas, onde foi replicada a problematização inicial citada anteriormente para duas turmas (6 e $7^{\circ}$ ano), totalizando 30 alunos. Ainda neste ano, na escola Riachuelo, nove turmas passam a compor o projeto $\left(3,4\right.$ e $5^{\circ}$ ano), totalizando 140 alunos e suas professoras regentes. Em ambas as escolas, utilizaram-se os mesmos procedimentos e estratégias nas ações desenvolvidas.

Participaram do Projeto professoras que atuam no ensino fundamental nos anos inicias e finais das disciplinas de Ciências, Matemática, Artes e Geografia, as quais associavam o conteúdo teórico com a prática das atividades desenvolvidas na horta.

\section{Material: as mudas, as ferramentas e o adubo}

Foram selecionadas espécies aptas ao clima e solo da região. Os canteiros estavam compostos por mudas de verduras e legumes diversificados, onde buscou-se, alternar cores, formas e cheiros. Além das mudas de alface roxa, alface verde, beterraba, couve, cebolinha e tomate, foram utilizadas sementes de salsa, cenoura e vagem. A utilização das sementes possibilitou demonstrar aos alunos as diferentes fases do desenvolvimento das plantas. No ano de 2017 foram plantadas 500 mudas, no ano de 2018, em torno de 600 mudas. Para dar forma aos canteiros e realizar o plantio das mudas, foram utilizados enxadas, regadores e colheres de jardim.

No que se refere à adubação, a orientação inicial foi de montar uma composteira e a partir desta, produzir o adubo orgânico, aproveitando os resíduos vegetais da própria escola, tais como: palhas, galhos, restos de culturas, cascas e polpas de frutas, pó de café, folhas e outros. Contudo, tal prática demanda maior tempo, pois é necessário esperar os resíduos se transformarem em adubo orgânico/húmus, desta forma, não foi adotada na escola da rede particular num primeiro momento. Na escola 
da rede pública, optou-se pelo plantio direto no solo, sem adubação inicial, ficando a composteira como a possibilidade de acesso a adubos futuramente.

$\mathrm{Na}$ escola da rede particular, buscando melhorar a qualidade do solo, optou-se pela utilização de adubo orgânico adquirido em casa agropecuária, para montar os canteiros. Um solo fértil deve apresentar uma quantidade razoável de matéria orgânica, reter água e ser permeável, e ainda apresentar os minerais essenciais para o cultivo (CLEMENTE, ABER, 2012). No total foram utilizados 16 sacos de $20 \mathrm{~kg}$ cada.

\section{O espaço: a horta}

Em ambas as escolas, as áreas destinadas para as hortas ficavam ao fundo das escolas. Optou-se por espaços que possibilitassem cercamento (evitar o trafego de animais), com acesso à água, exposição solar favorável ao desenvolvimento das plantas e com acessibilidade para os alunos, professores e pais. O plantio das mudas foi realizado diretamente no solo.

As turmas inseridas no Projeto seguiram um cronograma de atividades entre o preparo dos canteiros, plantio das mudas, manutenção, cuidados e colheita. Esse processo possibilitou maior cooperação e envolvimento mútuo entre todos e nas diversas fases do trabalho. Todas as crianças envolvidas plantaram as mudas, semearam nos canteiros e elaboraram uma forma de identificação para cada canteiro. A manutenção ocorreu com frequência de duas a três vezes por semana, para regar e acompanhar a evolução da horta, demonstrando, aos alunos, as diferentes fases de desenvolvimento das plantas.

\section{O PAPEL DA HORTA NA ESCOLA}

Atividades desenvolvidas com a horta na escola, colaboram para $\mathrm{O}$ desenvolvimento e adoção dos alunos de um estilo de vida mais saudável em seus hábitos alimentares. Além da integração e reflexão com a problemática ambiental, vivenciada a partir do universo da horta escolar (CRIBB, 2010).

O contato com a natureza é uma experiência muito válida para as crianças e adolescentes. A escola é um espaço social, onde muitas pessoas convivem, sendo um local de muitos aprendizados e construção do conhecimento. Assim, o espaço escolar é adequado para, por exemplo, trabalhar projetos referentes a saúde e a educação 
ambiental. Neste contexto, o projeto horta na escola, objeto deste estudo, é um excelente exemplo. Nas palavras de Morgado (2006, p. 1):

\begin{abstract}
A horta inserida no ambiente escolar pode ser um laboratório vivo que possibilita o desenvolvimento de diversas atividades pedagógicas em educação ambiental e alimentar unindo teoria e prática de forma contextualizada, auxiliando no processo de ensino-aprendizagem e estreitando relações através da promoção do trabalho coletivo e cooperado entre os agentes sociais envolvidos.
\end{abstract}

A Horta na escola, além de colocar o aluno em contato direto com o trabalho concreto, pode ser utilizado como um espaço de estudo para as diferentes disciplinas que compõem a grade curricular, de maneira interdisciplinar. O preparo oferece várias vantagens, entre as quais está a obtenção de alimentos variados a baixo custo, bem como, permite que o aluno tenha acesso e conheça as práticas de cultivo de alguns alimentos. Práticas estas, que podem ser reproduzidas em casa com a família, como o estímulo a prática de uma alimentação mais saudável.

Portanto, o consumo de hortaliças cultivadas em pequenas hortas, como a do objeto de estudo, auxilia na promoção da saúde. Para Cribb (2010), as atividades realizadas na horta escolar contribuem para a consciência dos alunos na alimentação mais saudável e a necessidade de preservação do meio ambiente. Também auxilia na capacidade do trabalho em equipe e da cooperação. Proporciona aproximação com a terra e seu cultivo, já que as crianças e jovens que residem na cidade possuem pouco contato com a natureza.

O convívio escolar é decisivo na aprendizagem de valores sociais e o ambiente escolar é o espaço de atuação mais imediato para os alunos. No mais, a escola ainda se diferencia por oportunizar de maneira efetiva um espaço de vivências e práticas de aprendizagem fora da sala de aula. Assim como proporcionar aos alunos o contato com verduras, legumes e hortaliças estimulando o interesse por esses alimentos (BRASIL, 1997).

A grande tarefa da escola é proporcionar um ambiente escolar saudável e coerente com aquilo que ela pretende que seus alunos aprendam. Para que assim possa, de fato, contribuir para a formação da identidade como cidadãos conscientes de suas responsabilidades com o meio ambiente e capazes de ter atitudes de proteção e melhoria em relação a ele (BRASIL, 1997). 
Neste contexto, a horta na escola é segundo Magalhães (2003, p. 5), uma estratégia, visando estimular o consumo de hortaliças e frutas. "As hortaliças cultivadas na horta escolar, fazem muito sucesso, ou seja, todos querem provar, pois é fruto do trabalho dos próprios alunos", fenômeno este já observado na ocasião da colheita em dezembro de 2018. A horta pode se tornar um instrumento facilitador do trabalho dos temas transversais, em especial dos seguintes: meio ambiente, saúde, trabalho e consumo, dentre outros assuntos a serem abordados no ensino fundamental (OLIVEIRA; PEREIRA; PEREIRA JUNIOR, 2018).

Para Cribb (2010), a horta escolar é o espaço adequado para que os educandos aprendam os benefícios de formas de cultivo mais saudáveis. Ao mesmo tempo, é um excelente momento para aprender sobre alimentação saudável, pois, em grande maioria, as crianças e adolescentes, não gostam de comer verduras e legumes. E o fato de cultivar o alimento pode ser um meio de estimular a inserir estes produtos em sua alimentação, além de saberem a origem dos vegetais, estes, são cultivados sem adição de insumos químicos.

O projeto de inserção da horta nas atividades escolares no município de Santa Maria/ RS, busca despertar nos alunos do ensino fundamental o interesse pelas atividades e cuidados necessários na produção de hortaliças. Envolvendo diretamente os alunos na produção de alimentos saudáveis, contextualizando os benefícios para saúde a partir do trabalho transdisciplinar entre as diferentes áreas do conhecimento.

Ou seja, o trabalho desenvolvido junto às escolas, possui como pressuposto associar a prática ao conhecimento teórico assimilado em sala acerca das temáticas: clima, fotossíntese, recursos hídricos, tipos de solo, saúde, meio ambiente, educação ambiental, crescimento das plantas, estações do ano, poluentes, formas geométricas, entre outros.

O diálogo aliado às práticas educativas possibilita que a educação ambiental ocorra de forma sistemática, difundindo conhecimento a toda comunidade escolar. Demonstrando a relevância desses temas na composição da integralidade das crianças, tornando-as cidadãos compromissados principalmente com o meio ambiente $\mathrm{e}$ alimentação saudável. 


\section{RESULTADOS E DISCUSSÕES}

A principal função do trabalho com o tema Meio Ambiente na escola foi contribuir para a formação de cidadãos conscientes, aptos a decidir e atuar na realidade socioambiental de um modo comprometido com a vida e com o bem-estar de todos. Esse é um grande desafio para a educação, seja através de gestos de solidariedade, hábitos de higiene pessoal e dos diversos ambientes, participação em pequenas ações e projetos são exemplos de aprendizagem que podem ocorrer na escola (BRASIL, 1997).

A horta preconiza alterações de valores e atitudes, quando constituída no espaço escolar, auxilia na constituição de alunos cidadãos. Ainda, possibilita uma aprendizagem efetiva, dotada de significados, relacionando conteúdos à práticas que podem ser replicadas no cotidiano de vivência das famílias.

De acordo com os PCNs para Meio Ambiente e Saúde, cabe à escola também garantir situações em que os alunos possam pôr em prática sua capacidade de atuação (BRASIL, 1997). Por isso é necessário que o conhecimento comece a ser repassado desde os primeiros anos de formação humana, contribuindo no desenvolvimento pessoal dos envolvidos (SANTOS et al., 2018). Desta forma, é importante promover situações no interior da escola que promovam a articulação com os problemas locais, e, se possível, estimular a participação de pessoas da comunidade ou de outras instituições (BRASIL, 1997).

Neste contexto, se insere o Projeto horta na escola. Que trabalha temáticas diretamente vinculadas a educação ambiental a partir de uma perspectiva transdisciplinar. Suas ações são pensadas e desenvolvidas a partir dos conhecimentos prévios dos sujeitos inseridos, buscando uma aprendizagem significativa ${ }^{1}$. Os exemplos, os problemas, a finalidade da aprendizagem nascem do que é o aluno concreto (Almeida, 2009, p. 82).

O resultado obtido através do diálogo entre as duas escolas foi significativamente distinto. Alunos da escola da rede municipal possuíam maiores conhecimentos a respeito das fases e materiais necessários para a construção da horta, o que deflagrou intimidade com o preparo de hortas em suas residências. Nesse mesmo sentido, evidenciou-se a importância socioeconômica das hortas no acesso a alimentos e

\footnotetext{
${ }^{1}$ A aprendizagem significativa caracteriza-se pela interação cognitiva entre o novo conhecimento e o conhecimento prévio. Nesse processo, que é não-literal e não-arbitrário, o novo conhecimento adquire significados para o aprendiz e o conhecimento prévio fica mais rico, mais diferenciado, mais elaborado em termos de significados, e adquire mais estabilidade (MOREIRA, 2005, p. 86).
} 
segurança alimentar de suas famílias. Estes, em sua maioria, encontravam-se inseridos numa situação econômica desfavorável, sendo a escola inclusive um local de acesso à alimentação via merenda escolar. A condição socioeconômica dificultou a realização plena das atividades na forma como havia sido proposta. A ausência de materiais e recursos dificultou a permanência das atividades na escola.

Por outro lado, a construção da horta obteve uma participação mais efetiva dos alunos da escola da rede particular de ensino, se mostrando como uma experiência nova, atrativa e positiva. Para estes, de forma geral, a referência da obtenção de alimentos, verduras e legumes, se restringia (até a aplicação do projeto) ao supermercado. Desta forma, todas as atividades estimulavam a curiosidade bem como expectativas aos resultados.

As fases

$\mathrm{Na}$ construção dos canteiros, por se tratar de crianças, as pesquisadoras atuaram de forma mais ativa nas escolas. Após a finalização, todas as demais etapas ficaram sob responsabilidade dos alunos e das professoras. A partir da Figura 2, é possível observar a fase inicial, ano de 2017, onde alunos estão preparando os canteiros, para posteriormente plantarem as mudas e sementes. As atividades foram desenvolvidas de forma satisfatória evidenciando o interesse dos alunos.

Com o inicio das atividades práticas na horta, as professoras começaram a trabalhar, na medida do possível, conteúdos que possibilitassem alguma relação com a mesma. O esforço ocorreu no sentido, de possibilitar uma aprendizagem efetiva. Para tanto, os professores precisam conhecer o assunto e buscar com os alunos mais informações, enquanto desenvolvem suas atividades (BRASIL, 1997). Salienta-se que as professoras tinham autonomia para trabalhar seus conteúdos a partir da didática que considerassem ser a mais adequada. As pesquisadoras atuaram diretamente na horta, realizando conversas com as professoras sempre que surgiam demandadas que exigiam formas de relacionar conteúdos às atividades da horta. 
Figura 2: Preparando os canteiros

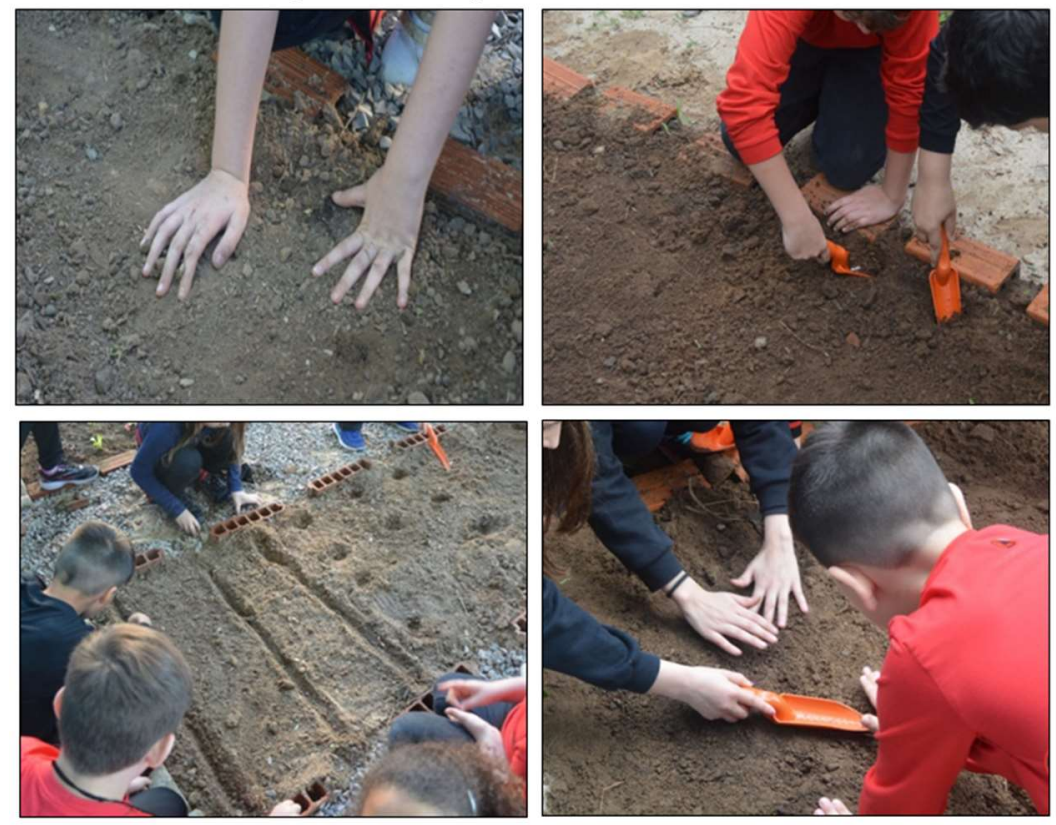

Fonte: autoras (2018).

A partir desta etapa, a professora de Matemática trabalhou, entre outros, conteúdos relacionados às medidas, formas geométricas, mapas itinerários com operações matemáticas, adaptando os conteúdos aos diferentes níveis em que os alunos se encontravam. Para trabalhar com as formas geométricas de forma prática a professora se dirigiu com os alunos para a horta, utilizou uma fita métrica, onde cada aluno realizava a medição dos lados e a partir destes a determinação da área e do perímetro. Também foi medido o distanciamento entre as plantas e assim pode ser determinado o número de plantas para o espaço disponível.

Em Ciências foi trabalhado sobre a fotossíntese, as fases de crescimento das plantas. Os alunos foram instigados a pesquisar quais hortaliças poderiam ser plantadas o ano todo na região Sul do Brasil, bem como, métodos naturais para resolver problemas com fungos e insetos na horta. A professora trabalhou diretamente na horta atividades práticas, nas quais os alunos acompanhavam o crescimento das plantas e sua relação com o processo da fotossíntese, e assim, passaram a compreender as diferentes fases de crescimento entre plantas cultivadas com mudas e sementes.

Em Geografia as diferentes regiões brasileiras com seus tipos de solos e climas e sua relação para o desenvolvimento das plantas. Os alunos compararam imagens de tipos de solos de livros com os presentes na horta, tentando estabelecer conexões para a compreensão das diferenças encontradas entre os canteiros da mesma horta. 
A professora, a partir da horta trabalhou de forma prática estes conteúdos, demonstrou aos alunos que as plantas dos canteiros se desenvolviam de forma diferente, ainda que as mudas tivessem a mesma procedência, plantadas no mesmo dia e da mesma forma, haviam diferenças no seu crescimento e desenvolvimento. Estas diferenças estavam também atribuídas ao tipo de solo presente em cada canteiro. No que se refere a interferência do clima, os alunos foram levados ao espaço da horta em diferentes estações do ano, onde acompanharam a influência da estação do ano na produção.

As professoras trabalhavam conjuntamente. As ações a serem realizadas no projeto eram definidas a partir das reuniões de planejamento, momento no qual, entre outros, organizavam os dias em que cada professor estaria a frente das atividades necessárias ao andamento da horta como regar as plantas e limpar os canteiros.

Os conhecimentos das três áreas citadas são trabalhados de forma conjunta, produzindo um saber dotado de significados, a fim de superar a compartimentalização dos saberes e proporcionar uma visão da complexidade (MORIN, 2002) da realidade presente. Desenvolver a postura crítica é muito importante para os alunos, pois isso lhes permite reavaliar as mesmas informações e os valores a elas associados (BRASIL, 1997).

Ou seja, uma educação participativa, inclusiva, compreendida em suas dimensões crítica e ativa. Nesse sentido, a escola atua como catalisadora das forças sociais promovendo a cidadania e o diálogo entre sujeitos e entre teoria e prática na perspectiva da transformação social que, necessariamente, inclui mudanças em todos os âmbitos da vida, incluindo a relação entre os seres humanos e, obviamente, suas trocas com a natureza.

Ao iniciar a fase de plantar as mudas e as sementes, conforme figura 3, foi possível observar que os alunos estavam comprometidos, realizando de forma correta as atividades a partir das abordagens e apontamentos feitos em sala. Nesta fase, cada turma a seu modo, identificou o canteiro pelo qual estava diretamente responsável. 
Figura 3: Plantando as mudas e as sementes
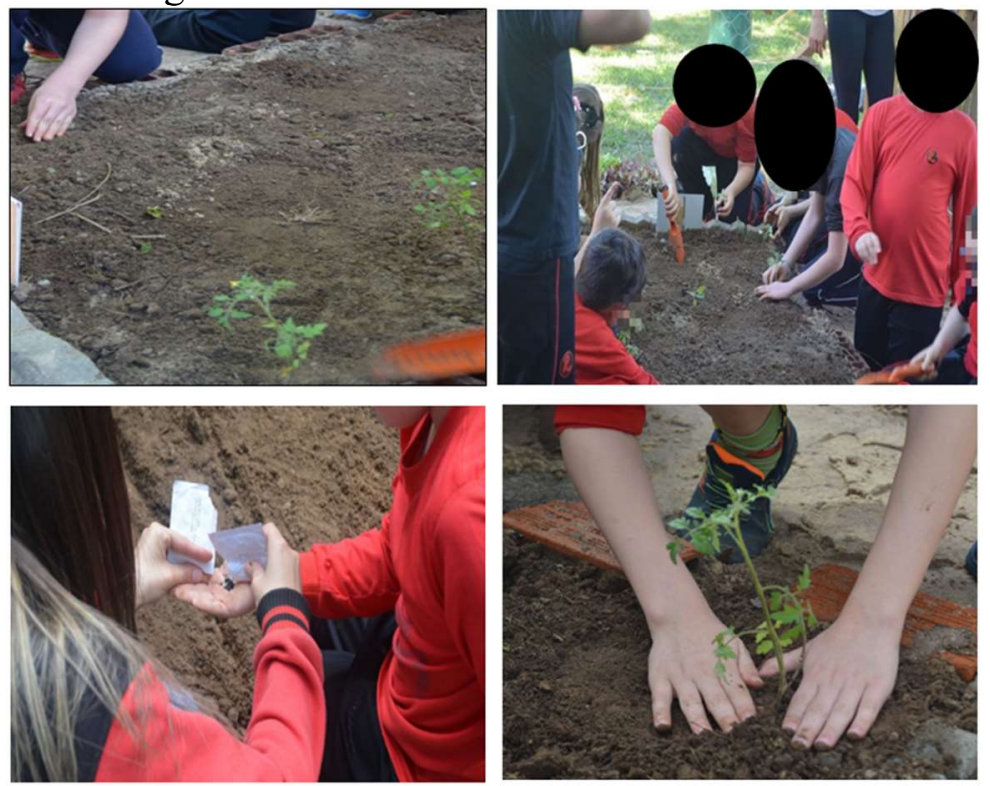

Fonte: autoras (2018).

O acesso as novas informações permite repensar a prática (BRASIL, 1997). Através da inserção da horta no espaço escolar, pôde-se demonstrar o alinhamento de acordo com o que Fridrich (2015), já havia constatado, ou seja, de que constituir como uma atividade experimental, interativa e vivenciada, onde o aluno encontre objetos presentes fisicamente que lhes possibilitem obter e interagir com dados do mundo natural. Pressupõe-se a participação do aluno em uma situação de ensino e aprendizagem em que se utiliza ou requer a análise e reflexão sobre dados primários da natureza.

A estrutura da escola, as ações dos integrantes do espaço escolar devem contribuir na construção das condições necessárias a desejada formação mais atuante e participativa do cidadão. Esta vivência permite aos alunos perceberem que a construção e a produção dos conhecimentos são contínuas e que, para entender as questões ambientais, há necessidade de atualização constante (BRASIL, 1997). A figura 4 apresenta o acompanhamento pelos alunos dos canteiros com diversificadas verduras. 
Figura 4: Acompanhando o crescimento das verduras e legumes
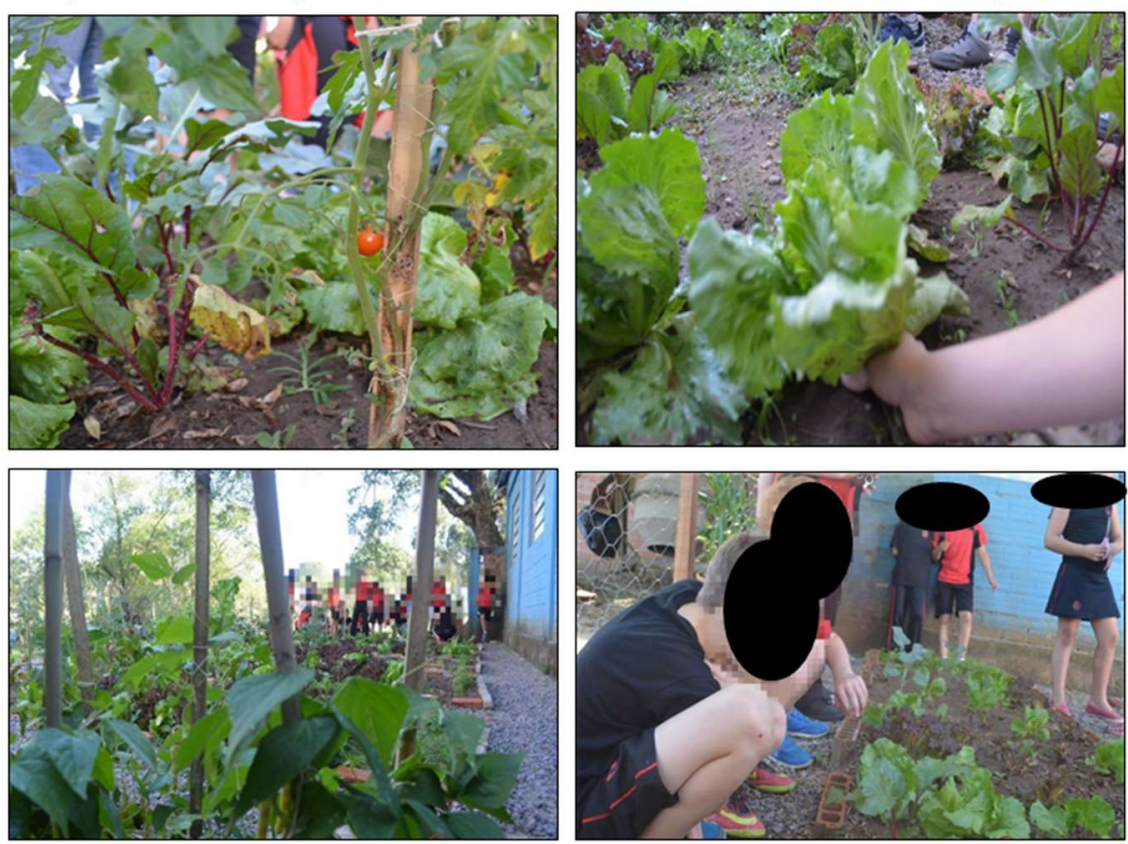

Fonte: autoras (2018).

A partir da figura 5, observa-se como o aspecto do local já se apresenta de forma diferente em relação a fase inicial, hortaliças em pleno crescimento, harmonia entre os canteiros.

Figura 5: Uma nova paisagem na Escola: a horta
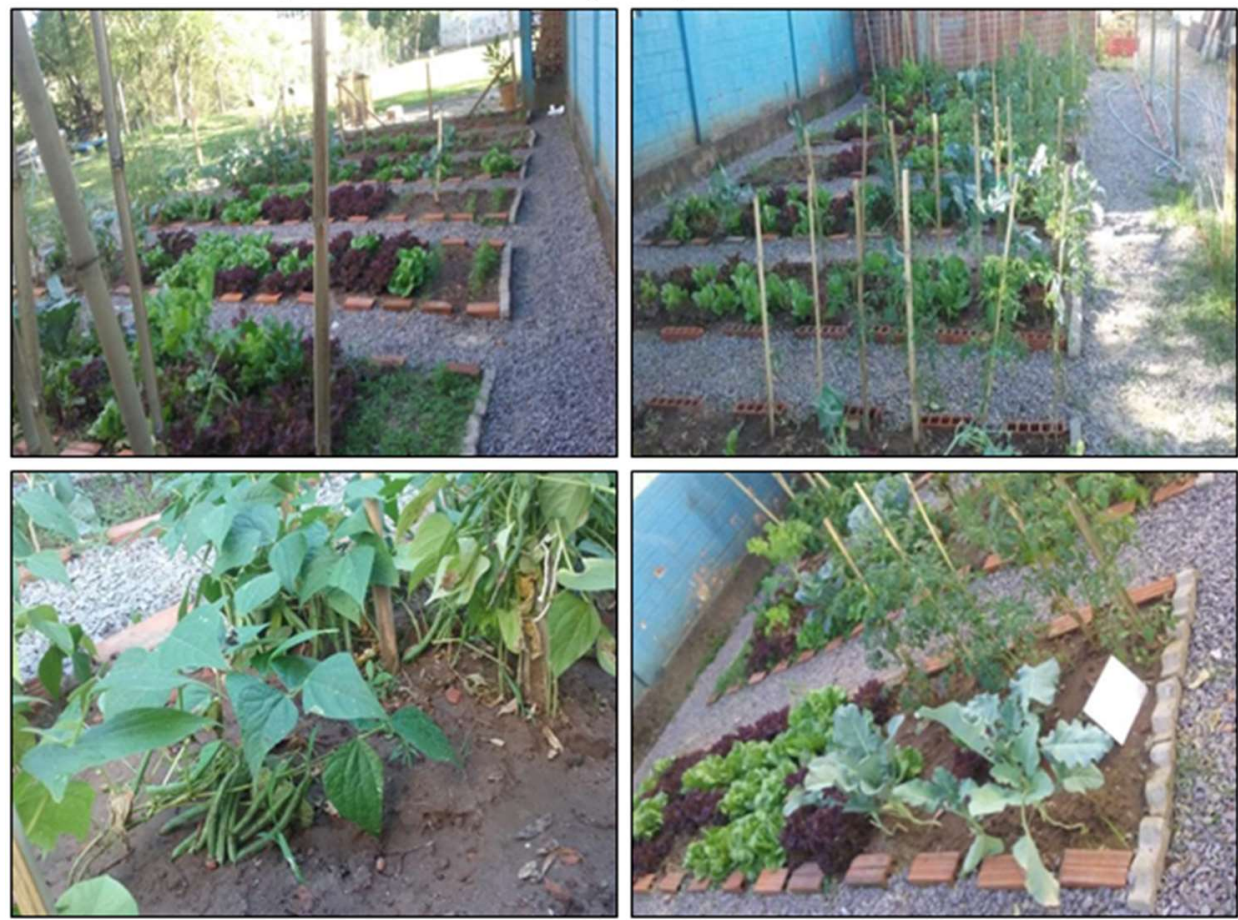

Fonte: autoras (2018). 
Em estudo efetuado em Florianópolis/SC, por Cunha, Sousa e Machado (2010), concluíram que há necessidade em incentivar os educandos no consumo de saladas, já que a maioria não gosta. E quando professores explicam a importância da ingestão frutas e verduras aos alunos, com frequência, perguntam se o professor faz dieta, pois, vinculam a ingestão de verduras e legumes a esta concepção. O projeto horta na escola, busca desconstruir essa "visão", compreende-se que os hábitos alimentares das crianças podem ser modificados a partir de estímulos. No momento em que cultivam seu próprio alimento e acompanham as fases de crescimento, passam a ter maior consciência da importância da alimentação e de sua influência na saúde.

De modo geral, o trabalho com esse tema transversal pode, se constituir num espaço revigorador da vida escolar, da prática pedagógica, aguçando o debate entre alunos de várias idades e classes, entre toda a comunidade escolar, entre escola e bairro (BRASIL, 1997).

A figura 6 mostra o entusiasmo dos alunos na hora da colheita, onde cada um recebeu uma embalagem para levar e consumir junto com a família as hortaliças plantadas e cuidadas por eles mesmos.

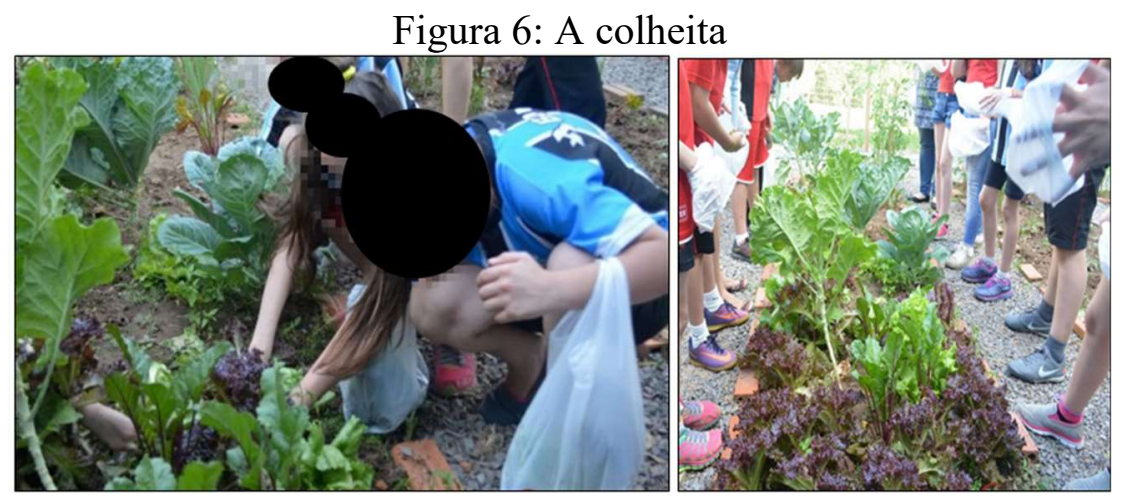

Fonte: autoras (2018).

A sociedade tem conhecimento que a alimentação saudável contribui diretamente na qualidade de vida, contudo, tal condição, ainda não é o suficiente para que se adotem a prática de uma refeição de qualidade (SANTOS et, al. 2018). Numa sociedade urbanizada, onde predomina a alimentação de produtos processados, o vínculo com o meio ambiente e o natural, torna-se cada vez mais distante.

É justamente, por esse motivo, que o projeto horta na escola tenha despertado o interesse de alunos, professores, gestores e pais. Esse projeto teve o objetivo de 
aproximar os alunos da natureza, criando um vínculo com o meio ambiente, influenciando na inserção de hábitos saudáveis pelo cultivo de verduras e hortaliças. Buscou-se construir junto aos alunos conhecimentos que possibilitassem que os mesmos replicassem a experiência em seus espaços de moradia, fenômeno este que ocorreu segundo relato de alguns pais. Pequenos espaços, ou canteiros de flores nas residências dos alunos acabaram se tornando espaços de cultivo de alimentos.

Finalmente, destacamos o quão gratificante foi desenvolver esse projeto onde as crianças se envolveram com alegria e entusiasmo, fazendo com que todas as atividades nas etapas fossem animadoras. Além disso, os alunos manifestaram prazer e euforia em se encarregarem da horta na escola. Os alunos também passaram a compreender a importância da educação ambiental e a relação que esta possui com a produção de alimentos saudáveis. A horta deixou o ambiente escolar mais atrativo, colorido e natural, sendo possível verificar até uma mudança no espaço físico da mesma, pois ocorreu uma maior inteiração entre os alunos com esses espaços ocupados pela horta, antes, ociosos.

O Projeto ocorreu de forma satisfatória entre os anos de 2017 e 2018, período em que foram acompanhados de formas contínuas os trabalhos. No ano de 2019 a escola da rede particular, motivada pelo resultado alcançado no projeto, iniciou a construção das instalações para uma horta suspensa, na parte frontal da escola, a qual servirá de laboratório com bancadas para o desenvolvimento de distintas práticas pedagógicas. $\mathrm{Na}$ escola da rede pública, o espaço da horta se manteve, outros projetos passaram a ocupar o espaço, entre estes, a produção do milho crioulo.

\section{CONSIDERAÇÕES FINAIS}

Crianças e adolescentes passam significativas horas de seu dia no espaço escolar. Os conhecimentos vinculados a uma aprendizagem significativa perpassam as fronteiras físicas da escola, se constituindo essenciais no desenvolvimento de um cidadão crítico e consciente. A escola é um espaço e um meio pelo qual se torna possível desenvolver de forma eficiente com os educandos distintas praticas educativas em relação aos espaços de vivência e a questão ambiental.

O projeto horta na escola se concretizou enquanto instrumento didático educativo, possibilitando um processo de ensino e aprendizagem significativo, a partir 
das interlocuções realizadas entre conteúdos e práticas, bem como, nas relações de respeito e reciprocidade construídas junto ao coletivo.

O acompanhamento dos alunos nas diferentes fases efetuadas na construção do espaço da horta escolar, incentivaram o consumo de verduras e legumes, estimulando a adoção de hábitos alimentares saudáveis. A partir do trabalho foi possível observar que os alunos passaram a ter uma postura mais crítica e consciente no que tange a proteção ambiental, assim como aguça a solidariedade ambiental, tornando-os multiplicadores desses conhecimentos e práticas adquiridos.

A mudança de postura dos alunos acerca da alimentação saudável e o aceite no consumo de hortaliças foi positiva, após a implantação da horta. A experiência da horta e a vivência em todas as fases, foi essencial.

Desta forma, conclui-se que, esse projeto, desenvolvido sem nenhum recurso público, de forma voluntária, foi significativo para aqueles estudantes, pela oportunidade de vivenciar, de forma prática, conhecimentos vinculados à temática ambiental e à alimentação saudável, assim como, proporcionou experiências no decorrer de todas as etapas da construção, manutenção e colheita dos produtos da horta.

O projeto horta na escola ganhou espaço e estimulou o interesse educativo, permanecendo em vigor no ano letivo de 2018, assim como abarcou mais turmas. Isso tudo foi possível em decorrência dos alunos terem levado suas experiências para casa, assim como as hortaliças produzidas na horta da escola para consumo junto às famílias, o que instigou os pais a conhecerem o espaço da horta e se colocarem à disposição para que as atividades continuassem. Neste contexto, ficou evidente que a escola cumpre múltiplas funções, entre as quais estão a promoção da saúde e a construção de valores e hábitos.

\section{AGRADECIMENTOS}

Agradecemos a equipe do Colégio Riachuelo, Santa Maria/RS, desde a Diretoria, professores envolvidos, servidores e alunos pelo apoio na implantação e desenvolvimento do Projeto. 


\section{REFERÊNCIAS}

Almeida, F. J. Paulo Freire. Folha Explica, v. 81. 2009. São Paulo: Publifolha. 95p.

BRASIL. MEC. Parâmetros Curriculares Nacionais: Meio Ambiente e Saúde. Brasília, MEC, 1997.

BRASIL. Lei No. 9795, de 27 de abril de 1999. Dispõe sobre a educação ambiental, institui a Política Nacional de Educação Ambiental e dá outras providências. Disponível em: < http://www.planalto.gov.br/ccivil 03/LEIS/L9795.htm>. Acesso em: 04 nov. 2019 .

CLEMENTE, F. M. V. T.; HABER, L. L.; Horta em pequenos espaços. Editoras Técnicas, $1^{\mathrm{a}}$ ed. Embrapa: Brasília - DF, 2012.

CRIBB, S. L. de S. P. Contribuições da educação ambiental e horta escolar na promoção de melhorias ao ensino, à saúde e ao ambiente. Revista Eletrônica do Mestrado Profissional em Ensino de Ciências da Saúde e do Ambiente (REMPEC). V.3, n 1, p. 42-60, 2010.

CUNHA, E.; SOUSA, A.A.: MACHADO, N.M.V. Alimentação orgânica e as ações educativas na escola: diagnóstico para educação em saúde e nutrição. Florianópolis (SC): Ciências \& Saúde Coletiva, v. 15, n.1, 2010. Disponível em: < http://www.scielo.br/scielo.php?pid=S1413-

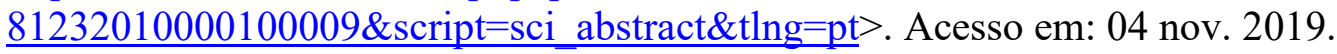

FREIRE, P. Educação como prática da liberdade. 23 ed. Rio de Janeiro: Paz e Terra, 1999.

FRIDRICH, G. A. Horta escolar: como alternativa para a Educação Ambiental. In: EDUCERE - XII Congresso Nacional de Educação. PUC, Paraná, 2015.

INSTITUTO BRASILEIRO DE GEOGRAFIA E ESTATÍSTICA - IBGE - Cidades. Disponível em: <https://cidades.ibge.gov.br/brasil/rs/santa-maria/panorama $>$. Acesso em: 10 mai. de 2019.

MAGAlHÃES, A. M. A horta como estratégia de educação alimentar em creche. Santa Catarina, 2003. 120f. Dissertação (Mestrado em agroecossistemas). Universidade Federal de Santa Catarina, Florianópolis, 2003.

MOREIRA, A. M. Aprendizagem Significativa Crítica. Indivisa, Boletín de Estúdios e Investigación, $\mathrm{n}^{\mathrm{o}}$ 6, pp. 83-101, 2005.

MORGADO, F. da S. A horta escolar na educação ambiental e alimentar: Experiência do Projeto Horta Viva nas escolas municipais de Florianópolis. Monografia (Graduação em Agronomia) - Universidade Federal de Santa Catarina, Florianópolis, 2006.

OLIVEIRA, F. R. de; PEREIRA, E. R.; PEREIRA JUNIOR, A. Horta escolar, Educação Ambiental e a interdisciplinaridade. In: Revista Brasileira de Educação Ambiental. Revbea, São Paulo, v. 13, $\mathrm{n}^{\mathrm{o}}$ 2, p. 10-31, 2018. Disponível em: $<$ https://www.researchgate.net/publication/326045115_Horta_escolar_Educacao_Ambi ental_e_a_interdisciplinaridade>. Acesso em: 14 nov. 2019.

ORGANIZAÇÃO MUNDIAL DA SAÚDE. O papel da horta na escola. Publicações OMS. Disponível em: < https://www.who.int/eportuguese/publications/pt/>. Acesso em: 10 fev. de 2018. 
MORIN, E. Os sete saberes necessários à educação do futuro. São Paulo: Cortez; Brasília: UNESCO, 2002.

SANTOS, A. P. da S. et al. Implantação de hortas escolares: a Educação Ambiental começa desde a infância. In: Congresso Internacional das Ciências Agrárias COINTER - PDVAGRO, 2018. Disponível em <https://cointer-pdvagro.com.br/wpcontent/uploads/2019/02/HORTA-COMUNIT\%C3\%81RIA-DE-BASE-

AGROECOL\%C3\%93GICA-COMO-FERRAMENTA-PARA-DESPERTAR-

VOCA\%C3\%87\%C3\%95ES-1-1.pdf>. Acesso 04 nov. 2019. 